\title{
Field evaluation of advanced controls for the retrofit of packaged air conditioners and heat pumps
}

\author{
Weimin Wang*, Srinivas Katipamula, Hung Ngo, Ronald Underhill, Danny Taasevigen, Robert Lutes \\ Pacific Northwest National Laboratory, Richland, WA 99352, USA
}

\begin{abstract}
This paper documents the magnitude of energy savings achievable in the field by retrofitting existing packaged rooftop air conditioner and heat pump units (RTUs) with advanced control strategies not ordinarily used for RTUs. A total of 66 RTUs on 8 different buildings were retrofitted with a commercially available advanced controller for improving operational efficiency. The controller features enhanced air-side economizer control, multi-speed fan control, and demand controlled ventilation. Of the 66 RTUs, 18 are packaged heat pumps and the rest are packaged air conditioners with gas heat. The eight buildings cover four building types and four climate conditions. Based on the performance data collected for approximately 1 year, the normalized annual energy consumption savings ranged between $22 \%$ and $90 \%$, with an average of $57 \%$ for all RTUs. The average fractional savings uncertainty was $12 \%$ at $95 \%$ confidence level. Normalized annual electricity savings were in the range between $0.47 \mathrm{kWh} / \mathrm{h}(\mathrm{kWh}$ per hour of RTU operation) and $7.21 \mathrm{kWh} / \mathrm{h}$, with an average of $2.39 \mathrm{kWh} / \mathrm{h}$. RTUs greater than $53 \mathrm{~kW}$ and runtime greater than 14 hours per day had payback periods less than 3 years even at electricity price of $\$ 0.05 / \mathrm{kWh}$.
\end{abstract}

Keywords: Packaged air conditioner; Packaged heat pump; Retrofit; HVAC control; Field test

\section{Introduction}

RTUs are factory-made, self-contained equipment comprising a number of off-the-shelf components available in standard design and cooling capacities. In the U.S., RTUs are used in 46\% (2.1 million) of all commercial buildings, serving over $60 \%\left(3.6\right.$ billion $\mathrm{m}^{2}$ ) of the commercial building floor space [1]. The site cooling energy consumption associated with RTUs is about $2.4 * 10^{8} \mathrm{GJ}$ annually. Therefore, even a small improvement in the operational efficiency of these units can lead to significant reductions of national energy use and carbon emissions.

Most packaged units in the field use "standard" conventional control strategies. The compressor or gas furnace cycles on or off to maintain the space set point while the supply fan operates continuously at the design speed during occupied periods to meet the space ventilation requirement. Although many RTUs are equipped with economizer dampers, industry studies have shown that over $60 \%$ of them do not operate correctly [2]. It is common that the economizer control strategies in existing RTUs cannot take full advantage of outside air for free cooling. For example, all RTUs tested in this work used a fixed drybulb temperature as the high limit for economizer controls before they were retrofitted with the advanced controllers. Under this economizer control strategy, the outdoor-air damper is fully open when the outdoor-air temperature is less than $12.8^{\circ} \mathrm{C}$ and the thermostat calls for cooling. Otherwise, the damper is set to its minimum position even if the outdoor air is beneficial to address cooling loads.

Many retrofit opportunities exist to improve the operational efficiency of packaged air conditioners. Criscione [3] reported that several add-on controllers are emerging for RTU retrofits. Simulation studies

*Corresponding author. Tel: 1-509-368-7862; E-mail address: weimin.wang@pnnl.gov 
$[4,5,6]$ were made previously to investigate the magnitude of energy and cost savings that can be achieved from advanced RTU controls. For example, simulation results from Wang et al. [6] showed that simply adding multi-speed supply-fan control and demand-controlled ventilation to packaged air conditioners leads to energy savings of between $14 \%$ and $42 \%$ and cost savings between $27 \%$ and $59 \%$ for 16 locations covering all 15 climate zones in the U.S. The savings could be even higher for packaged heat pumps [7]. However, except for simulation studies, there is little solid work to validate the magnitude of energy and cost savings that can be achieved from RTU control retrofits in the field. Sunde et al. [15] presented the results from a pilot field demonstration of an RTU retrofit technology (digi-RTU Optimizer) that utilizes one variable-frequency drive (VFD) to modulate both the supply fan and compressor speed of the RTU. Based on 24 RTUs in the service territory of Omaha Public Power District, the test data over a couple of months showed that the digi-RTU Optimizer technology can reduce the average peak electricity demand by $39 \%$ and annual electricity savings by $56 \%$. Doebber et al. [16] tested the same RTU advanced controller as used in this paper. Performed in Hawaii, their tests included 9 RTUs in three buildings. Over the test period of three to six months, they found that the advanced controller achieved from 5\% to $15 \%$ annual energy savings at the building level.

To enhance the confidence of the utilities and building owners to adopt the advanced RTU controls for retrofits, an extensive field test is needed to cover more climate conditions, RTU capacities, different building types, and robust uncertainty analysis. . This paper presents the major findings from the field test performed from 2012 to 2013. The results from this work are important for building owners and utility companies to evaluate the financial merits of existing RTU retrofits with advanced controllers.

\section{Advanced RTU controller description}

The advanced controller used in this field test was designed to convert existing constant-air-volume rooftop units to highly efficient single-zone and variable-air-volume units. Upgrading an RTU with the advanced controller involves installation of a VFD and several sensors. The advanced controller can operate in conjunction with existing thermostats or building automation system. The controller monitors the thermostat signals or building automation system commands for heating and cooling and modulates the supply-fan speed and outdoor-air damper opening. The advanced controller can also work as a standalone building management system. In this case, the controller uses space temperature sensor readings, heating and cooling temperature set points, and the occupancy schedule to generate control signals. The following subsection describes the strategies used in the advanced controller for integrated air-side economizers, sequence of cooling stages, supply-fan speed controls, and demand-controlled ventilation.

\subsection{Integrated air-side economizer controls}

The advanced controller provides integrated economizer control based on differential dry-bulb temperature or differential enthalpy. To realize the economizer control based on differential dry-bulb temperature, a temperature sensor needs to be mounted in the return-air duct. To realize the control based on differential enthalpy, additional relative humidity sensors are needed for the outdoor air $(\mathrm{OA})$ and the return air. By full integration with the mechanical cooling system, the economizer can use $100 \%$ outdoor air to provide as much cooling as possible when the outdoor-air condition is favorable.

\subsection{Sequence of cooling stages}

When the space calls for cooling, the advanced controller uses the outdoor-air temperature as the trigger point to determine the unit's operation at different cooling stages. A cooling stage can be economizer only, economizer integrated with mechanical cooling, or mechanical cooling only. The controller has the following sequence of cooling stages: 
- If the outdoor-air temperature is below the compressor lockout set point at $14.4^{\circ} \mathrm{C}$, the economizer is used for both the first and the second stage cooling but with different fan speeds.

- If the outdoor-air temperature lies in between $14.4^{\circ} \mathrm{C}$ and $21.1^{\circ} \mathrm{C}$, the air-side economizer is used for the first stage of cooling and economizer integrated with the first stage compressor for the second stage of cooling.

- If the outdoor-air temperature is above $21.1^{\circ} \mathrm{C}$, the stages of compressor cooling are initiated corresponding to the call of cooling stages. In both stages, the air-side economizer is used together with mechanical cooling if the outdoor-air condition is favorable.

\subsection{Supply-fan speed controls}

Through the added VFD, the advanced controller modulates the supply-fan speeds based on the RTU primary operational modes including ventilation, heating, and cooling. The rooftop unit operates in the ventilation mode if 1) the sensed space temperature lies between the heating and cooling set points, and 2) the space is scheduled to be occupied. The heating operational mode is called on if the sensed space temperature is less than the heating set point. Once heating is initiated, it continues until the space temperature rises above the heating set point plus a differential. Similarly, the cooling operational mode is called on if the sensed space temperature is greater than the cooling set point. Once cooling is initiated, it continues until the space temperature decreases below the cooling set point minus a differential. Detailed discussions of these operation modes can be found in Wang et al. [6]. Table 1 lists the fan speeds at different operational modes. When the RTU operates in the ventilation mode, the supply fan runs at $40 \%$ of its design speed. In the cooling mode, the fan speed varies according to the outdoor-air temperature and the stage of cooling. In the heating mode, for RTUs with staged gas furnaces, the supply fan runs at $75 \%$ and $90 \%$, respectively, for the first and the second heating stages. For heat pumps and RTUs with one single stage of gas heating, the supply fan runs at $90 \%$ of its design speed.

Table 1: Supply-fan speed settings of the advanced RTU controller

\begin{tabular}{|l|l|l|l|}
\hline \multicolumn{2}{|c|}{ Operational mode } & $\begin{array}{l}\text { Outdoor air } \\
\text { temperature }\left({ }^{\circ} \mathbf{C}\right)\end{array}$ & $\begin{array}{l}\text { Fan } \\
\text { speed }\end{array}$ \\
\hline \multirow{3}{*}{ Cooling } & \multirow{2}{*}{1 st stage } & $<14.4$ or $>21.1$ & $75 \%$ \\
\cline { 2 - 4 } & 2nd stage & $\geq 14.4$ and $\leq 21.1$ & $90 \%$ \\
\hline \multirow{3}{*}{ Heating } & 1st stage (furnace) & Any & $90 \%$ \\
\cline { 2 - 4 } & 2nd stage (furnace) & Any & $75 \%$ \\
\cline { 2 - 4 } & heat pump & Any & $90 \%$ \\
\hline \multicolumn{2}{|l|}{ Ventilation } & Any & $90 \%$ \\
\hline
\end{tabular}

\subsection{Demand-controlled ventilation (DCV)}

The advanced controller uses the return-air $\mathrm{CO}_{2}$ measurement as the trigger point to modulate the OA damper opening. If the measured $\mathrm{CO}_{2}$ concentration is less than the $\mathrm{CO}_{2}$ set point of $1000 \mathrm{ppm}$, the OA damper is modulated to the minimum position necessary to meet the ventilation needs. For all tested RTUs in this study, the minimum amount of OA for ventilation was set at 5\% of the design supply air flow corresponding to the $100 \%$ fan speed. At other fan speeds, the minimum damper position was simply calculated by dividing $5 \%$ by the fan speed. For instance, when the fan runs at $40 \%$ of its full speed, the minimum OA damper position is set at $5 \% / 40 \%=12.5 \%$. If the measured $\mathrm{CO}_{2}$ concentration is greater than the $\mathrm{CO}_{2}$ set point, the OA damper is opened further until the calculated outdoor-air volume matches the design ventilation. There is no need to provide more than the design ventilation [8]. For 
example, for an RTU with the design ventilation set at 30\% of the design supply flow rate, the OA damper can be opened up to $75 \%$ in response to DCV if the unit runs in the ventilation mode (fan speed = $40 \%$ ). The above simplified approach of OA damper modulation does not account for the possible nonlinear relationships between the damper position and the OA flow.

\section{Overview of the retrofitted RTUs}

A total of 66 RTUs on 8 different buildings were retrofitted with the advanced controller. Table 2 provides a summary of the building sites, including the location, the building type, number of RTUs tested and the RTU type. Table 2 shows the following:

- The tested RTUs are located in four states in the U.S. with different climates. These locations fall into the following climate zones: Cleveland, $\mathrm{OH}$ (5A, cool and humid climate); Oaks, PA (4A, mixed and humid climate), Valencia, CA (3B, warm and dry climate), and all the sites in WA ( $4 \mathrm{C}$, mixed and marine climate). Details on the climate zone definition can be found in ASHRAE Standard 90.1 [9].

- The building types cover mercantile (both retail and shopping malls), office, food sales, and healthcare.

- Of the 66 tested RTUs, 18 are packaged heat pumps (HP) and the rest are packaged air conditioners with gas heat (AC).

Table 2: Summary of buildings participating in the field test

\begin{tabular}{|l|l|l|l|c|l|}
\hline Site ID & Location & Climate zone & Building type & $\begin{array}{l}\text { Number of } \\
\text { RTUs }\end{array}$ & $\begin{array}{l}\text { RTU } \\
\text { type }\end{array}$ \\
\hline 28 & Lynnwood, & 4C & Mercantile (malls) & 28 & AC \\
\hline 39 & Cleveland, OH & 5A & Healthcare & 2 & AC \\
\hline 40 & Oaks, PA & 4A & Mercantile (retail) & 8 & AC \\
\hline 41 & Kent, WA & 4C & Office & 1 & HP \\
\hline 43 & Everett, WA & 4C & Office & 6 & HP \\
\hline 44 & Federal Way, & 4C & Mercantile (malls) & 11 & HP \\
\hline 46 & Valencia, CA & 3B & Food sales & 5 & AC \\
\hline 51 & Bellevue, WA & 4C & Mercantile (retail) & 5 & AC \\
\hline
\end{tabular}

The tested RTUs have varied nameplate cooling capacities: 7 units are less than $35 \mathrm{~kW} ; 43$ units are in between $35 \mathrm{~kW}$ and $53 \mathrm{~kW}$; and 16 units are greater than $53 \mathrm{~kW}$. In addition to the cooling capacity, many other static data (such as RTU makes, models, and damper settings for design ventilation) were collected, but they are not presented here because of space limitation. More details can be found in Wang et al. [10].

\section{Field measurement and monitoring}

The same metering and monitoring plan was used on all 66 RTUs to estimate the energy savings from retrofitting the RTUs with the advanced controller. Each RTU had the following sensor measurement capabilities:

- A thermistor-type temperature sensor was used to measure the outdoor-air temperature, the return-air temperature, the mixed-air temperature right after the dampers, and the discharge-air 
temperature downstream of the cooling coil. At some buildings where the advanced controller was used as a building management system, the space temperature was also monitored. The accuracy of the temperature sensor is $\pm 0.2^{\circ} \mathrm{C}$.

- A power transducer was used to measure the total RTU power consumption. The power measurement has an accuracy of $\pm 0.5 \%$ of the meter reading.

- $\mathrm{A} \mathrm{CO}_{2}$ sensor was used to measure the $\mathrm{CO}_{2}$ concentration in the return duct. The $\mathrm{CO}_{2}$ sensor has an accuracy of $\pm 30 \mathrm{ppm}$.

In addition to the temperature, power and $\mathrm{CO}_{2}$ sensor measurements, a number of control signals such as space occupancy status, cooling calls and heating calls were also monitored. All sensor measurements and control signals were recorded at 1-minute intervals.

During the field tests, the RTU control logic was alternated daily between the conventional control and the advanced energy saving control. During the conventional control operation, the supply-fan speed ran at $100 \%$ when the RTU was in operation; the air-side economizer was not integrated with mechanical cooling and it was controlled with a fixed dry-bulb temperature at $12.8^{\circ} \mathrm{C}$; and the demand-controlled ventilation was not used. During the advanced energy saving control operation, the supply fan ran at different speeds depending on the RTU operational modes, as shown in Table 1; the air-side economizer was integrated with mechanical cooling and it was controlled with differential dry-bulb temperature controls; and the demand-controlled ventilation was enabled.

The conventional control was intended to emulate the RTU operation before retrofitting the controller. Thus, the test days with the conventional control operation formed the pre-retrofit period while the days with the advanced energy saving control formed the post-retrofit period. The alternating RTU operations between the above two control logic continued until sufficient test data covering different weather conditions were collected. On average, the tested RTUs had 109 days of data for the pre-retrofit period and 173 days for the post-retrofit period.

\section{Energy savings estimation methodology}

The methodology used to estimate energy savings from the RTU controller retrofit closely followed ASHRAE Guideline 14-2002 [11]. The procedure consists of three major steps: 1) regression model development, 2) energy savings calculation; and 3) savings uncertainty estimation, as discussed below.

\subsection{Regression model development}

The 1-minute monitored data cannot be used directly for regression model development because 1) some "bad" data points (e.g., stale data caused by lost communication between the controller and the archived database) may exist, and 2) the 1-minute time resolution is not the best resolution for models used to estimate energy savings [12]. Therefore, the raw monitored data were preprocessed by filtering out "bad" data and aggregating the 1-minute data into daily data suitable for regression model development.

Regression models were used to correlate the daily RTU electricity consumption with the average outdoor-air temperature. Theoretically, these regression models can have one to five parameters depending on building types and their energy-use pattern [11]. Based on the review of several RTUs' scatter charts showing the relationship between RTU's energy use and outdoor-air temperature, it was found that the three-parameter (3-P) and the five-parameter (5-P) change-point models were appropriate. The change point is a threshold below (above) which mechanical cooling (heating) is not needed to maintain the space temperature. The 5-P change-point model was applied to the total electricity for heat pumps. The 3-P change-point model was applied to the total electricity consumption for air conditioners with natural gas for heating. 
For packaged air conditioners with gas heat, the 3-P change-point model was used to correlate the daily average electricity consumption (including compress or for cooling, fan, and the parasitic energy for equipment control) with the average outdoor-air temperature. The model can be expressed with the following equation:

$R T U E_{\text {daily }}=C_{C F}+B_{C} *\left(T A O A-T_{C C P}\right)_{+}$,

where $R T U E_{\text {daily }}$ is the daily average RTU electricity consumption in $\mathrm{kWh} / \mathrm{h}$; and $C_{C F}, B_{C}$, and $T_{C C P}$ are regression coefficients; TAOA refers to the average outdoor-air temperature in ${ }^{\circ} \mathrm{C}$; and the subscript " + " means that only positive values of the parenthetical expression are considered.

For packaged heat pumps, the 5-P change-point model was used to correlate the daily average electricity consumption (including compressor for both heating and cooling, fan, and the parasitic energy for equipment control) with the average outdoor-air temperature. The model takes the following functional form:

$R T U E_{\text {daily }}=C_{H C}-B_{H} *\left(T_{H C P}-T A O A\right)_{+}+B_{C} *\left(A v g O A T-T_{C C P}\right)_{+}$,

where $C_{H C}, B_{H}$ (negative), $B_{C}, T_{H C P}$ and $T_{C C P}$ are regression coefficients.

Two important points need to be mentioned for Equations 1 and 2:

- The average outdoor-air temperature (TAOA) was computed using only the data when the space was occupied. The data collected in non-occupied hours were not used because RTUs were not running during those periods. Hence, TAOA differs from the daily average outdoor-air temperature conventionally used in literature, which covers the entire 24 hours.

- The daily average RTU electricity consumption ( $\left.R T U E_{\text {daily }}\right)$ was obtained by dividing the daily electricity consumption by the RTU runtime during. Prior to normalization by RTU runtime, daily electricity consumption is not suitable for regression model development because the daily runtime may vary for a given RTU. The varying runtime was caused by any of the following reasons: 1) the scheduled RTU operation hours differ between weekdays and weekends; 2) if an RTU implements the optimal start control, its start time varies with the outdoor-air temperature; and 3) the number of data records filtered out in the preprocessing process varies.

For each RTU, two regression models were developed: one for the pre-retrofit period and the other for the post-retrofit period. The Energy Charting and Metrics (ECAM) spreadsheet tool was used to develop the regression models based on the daily average electricity consumption and the average outdoor-air temperature. Available as a free add-on for Microsoft Excel, ECAM makes extensive use of Excel pivot tables. Development of regression models is one of ECAM's many key features, including data visualization to support building re-tuning and retro-commissioning. More details on ECAM's functionalities and its use can be found in Taasevigen et al. [13].

\subsection{Energy savings calculation}

The regression models were used to determine energy savings from the advanced controller in two ways: actual savings and normalized savings [11]. To obtain the actual savings, the pre-retrofit regression model was used with actual monitored data (i.e., average daily outdoor-air temperature and actual runtime) from the post-retrofit period to estimate the projected energy consumption with conventional controls. The differences between the projected energy use and the measured actual energy use during the post-retrofit period were summed to obtain the actual savings, as indicated in Eq. 3 below.

$R T U E_{\text {actsave }}=\sum_{i=1}^{m}\left(R T U E_{\text {prj }, i}-R T U E_{\text {meas }, i}\right) \quad$, 
where $R T U E_{\text {actsave }}$ is the actual electricity savings in $\mathrm{kWh} ; m$ stands for the total number of days in the post-retrofit period; the subscript $i$ represents the day index, prj and meas, respectively, represent the projection and actual measurement over the post-retrofit period.

The projected RTU electricity consumption was calculated from the pre-retrofit regression model along with the daily average outdoor-air temperature during the post-retrofit period. For example, for an RTU with gas heat, the projected daily RTU electricity use $(\mathrm{kWh})$ was calculated as:

RTUE $_{\text {prj }, i}=\left[C_{C F}+B_{C} *\left(\text { TAOA }_{i}-T_{C C P}\right)_{+}\right]_{\text {pre }} *$ RunTime $_{i}$,

where the subscript pre indicates the pre-retrofit regression model is applied; RunTime is the RTU running time (hours) at a given day in the post-retrofit period. Daily RTU runtime is used in Eq. 4 because the regression model was based on the RTU electricity consumption normalized by the runtime.

The actual energy savings are for specific measurement periods, which are less than 1 year and vary with different units. In addition, the weather experienced during that period may not represent the typical weather conditions in a particular location. Therefore, normalized annual energy savings based on the typical meteorological year (TMY) weather data are helpful to understand the impact of the advanced controller and compare the savings for different units. To obtain the normalized savings, both the pre- and post- retrofit models were used with TMY weather data to estimate RTU yearly electricity consumption under the two control logics. The differences between the estimated energy use from the pre- and postretrofit regression models were summed to obtain the normalized annual savings, as indicated in Eq. 5 below.

$R T U E_{\text {normsave }}=\sum_{i=1}^{365}\left(R T U E_{\text {pre }, i}-R T U E_{\text {post }, i}\right)$,

where $R T U E_{\text {normsave }}$ is the normalized electricity savings in $\mathrm{kWh}$ per year; the subscripts pre and post, respectively, represent the projection based on the pre- and post- retrofit regression models. In Eq. 5, the regression models were driven by the scheduled RTU running hours and the corresponding average outdoor-air temperature from TMY data.

After the absolute energy savings are calculated, percentage savings can be also calculated. For example, the actual percent savings for RTU electricity consumption $\left(F_{\text {actsave }}\right)$ was calculated as:

$F_{\text {actSave }}=\frac{R T U E_{\text {actsave }}}{\sum_{i=1}^{m} R T U E_{\text {prj }, i}} * 100 \%$,

\subsection{Savings uncertainty estimation}

According to ASHRAE [11], the following three primary sources of quantifiable uncertainty shall be considered in savings determination:

- Sampling uncertainty generated from not measuring the entire set. Because this field study was intended to measure the savings potential of each RTU, the sampling uncertainty was not considered.

- Measurement error generated from the calibration, range, and repeatability of meters and installation effects. Measurement errors need to be estimated for non-billing energy use meters and the measurements of post-retrofit independent variables. Thus, in this work, the sources of measurement equipment errors came from the electric power meter and the outdoor-air temperature sensor.

- Modeling uncertainty generated from the prediction error of the regression models. 
The fractional savings uncertainty, expressed as the ratio of the expected savings uncertainty to the total savings, was estimated for both actual savings and normalized savings. For actual savings, the fractional savings uncertainty was calculated as:

$U_{\text {actsave }}=\left(U_{\text {model }}^{2}+U^{2}{ }_{i v}+U_{\text {meter }}^{2}\right)^{0.5}$,

where $U_{\text {actsave }}$ indicates the actual savings uncertainty; the subscripts model, iv, and meter refer to the uncertainty from the regression model, the independent variable (i.e., outdoor-air temperature sensor) measurement error, and the power meter measurement error, respectively.

The references $[10,11]$ provide more detailed procedures and equations used to calculate each item of Eq. 7.

For normalized savings, the fractional savings uncertainty was calculated as:

$U_{\text {normsave }}=\frac{\Delta E}{\left|R T U E_{\text {normSave }}\right|}$,

where $\Delta E$ is the absolute uncertainty in electricity savings ( $\mathrm{kWh}$ ); and $R T U E_{\text {normsave }}$ is the normalized annual electricity savings calculated from Eq. 5.

The absolute savings uncertainty $\Delta \mathrm{E}$ was calculated using Equation 9 below [14]:

$\Delta E=\left(\Delta E_{\text {pre }}^{2}+\Delta E_{\text {post }}^{2}\right)^{0.5}$,

where $\Delta E_{\text {pre }}$ and $\Delta E_{\text {post }}$ are the absolute savings uncertainty for the pre-retrofit and post-retrofit regression models. They were calculated using the following equations:

$\Delta E_{\text {pre }}=t_{\text {pre }} * 1.26 * C V_{\text {pre }} *\left(\frac{n_{\text {pre }}+2}{n_{\text {pre }} * m_{T M Y}}\right)^{0.5} * \sum_{i=1}^{365} R T U E_{\text {pre }, i}$,
$\Delta E_{\text {post }}=t_{\text {post }} * 1.26 * C V_{\text {post }} *\left(\frac{n_{\text {post }}+2}{n_{\text {post }} * m_{T M Y}}\right)^{0.5} * \sum_{i=1}^{365} R T U E_{\text {post }, i}$,

where $t_{\text {pre }}$ and $t_{\text {post }}$ are the t-statistics determined from the confidence level and the number of data points, $C V_{\text {pre }}$ and $C V_{\text {post }}$ are the coefficients of variation of the root mean square error for the pre- and post-retrofit regression models; $n_{\text {pre }}$ and $n_{\text {post }}$ are the numbers of data points (i.e., days) used to develop the pre- and post- retrofit regression models; $m_{T M Y}$ is the number of days when the RTU is scheduled to operate.

\section{Energy savings results and discussion}

Based on the methodology presented in Section 5, actual energy savings, normalized energy savings and their uncertainties were calculated for each RTU. This paper focuses on the results for each individual unit. The report [10] provides aggregated results for sites, RTU size ranges, and RTU types.

\subsection{Percentage of energy savings}

Figure 1 provides the actual percent energy savings for each RTU together with the uncertainty bands at 95\% confidence level. RTU 212 is used as an example to illustrate the approach of deriving the savings range from uncertainty. RTU 212 had $67 \%$ of actual electricity savings with $12 \%$ uncertainty at $95 \%$ confidence. The expected range of electricity savings for this RTU was calculated as $67 \% \pm$ $(67 \% * 12 \%)=67 \% \pm 8 \%$. This means that RTU 212 has no less than $59 \%$ electricity savings at $95 \%$ confidence level. ASHRAE Guideline 14 [11] specifies that the maximum acceptable level of uncertainty is $50 \%$ of annual savings at $68 \%$ confidence. Because the savings uncertainty presented in this work used 
95\% confidence, the maximum acceptable uncertainty was adjusted to $100 \%$ after considering the difference of t-statistics corresponding to the two confidence levels. Figure 1 covers only 62 of all 66 units because 1) 2 units were usually offline throughout the test period and therefore did not generate a sufficient amount of data for regression model development; and 2) 2 units had their savings uncertainties greater than the maximum acceptable uncertainty at $95 \%$ confidence. Figure 1 and its underlying data lead to the following:

- The percentage of actual RTU electricity savings was in the range between $22 \%$ and $91 \%$, with an average of $56 \%$. The fractional uncertainty for actual RTU electricity savings ranged between $2 \%$ and $77 \%$, with an average of $22 \%$. Most units had their savings uncertainty much less than the maximum level of uncertainty to meet ASHRAE Guideline 14 requirements.

- As the percentage of electricity savings increases, the uncertainty usually decreases and the error bar gets shorter. Units with a higher percentage of savings were running in ventilation or economizer modes (only fan running). Because there is little variation in fan energy versus outdoor-air temperature, the modeling uncertainty is low for those units.

Similarly, Figure 2 shows the percentage of normalized annual savings and the uncertainty bars at $95 \%$ confidence level. The percentage of normalized annual RTU electricity savings was in the range between $22 \%$ and $90 \%$, with an average of $57 \%$. The fractional uncertainty for normalized RTU electricity savings ranged between $1 \%$ and $51 \%$, with an average of $12 \%$. Most units had the normalized savings uncertainty lower than the corresponding actual savings uncertainty. This is because 1) the source of measurement error was not accounted for in the calculation of normalized savings uncertainty; and 2) the post-retrofit period had more data points when calculating the normalized savings uncertainty. 


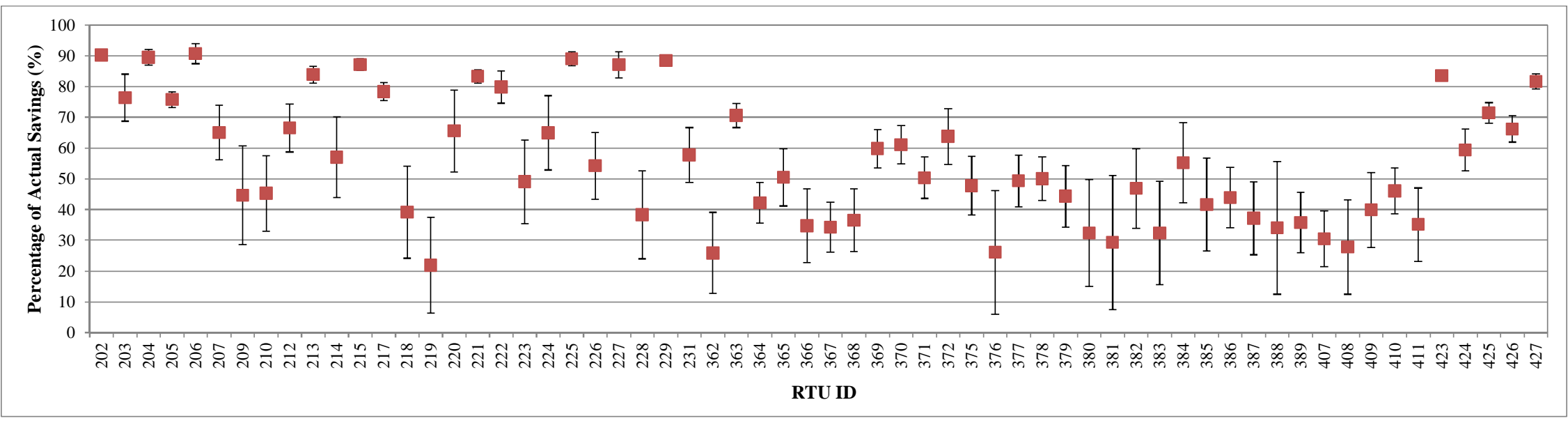

Figure 1: Percentage of actual energy savings and uncertainty range at 95\% confidence for each RTU

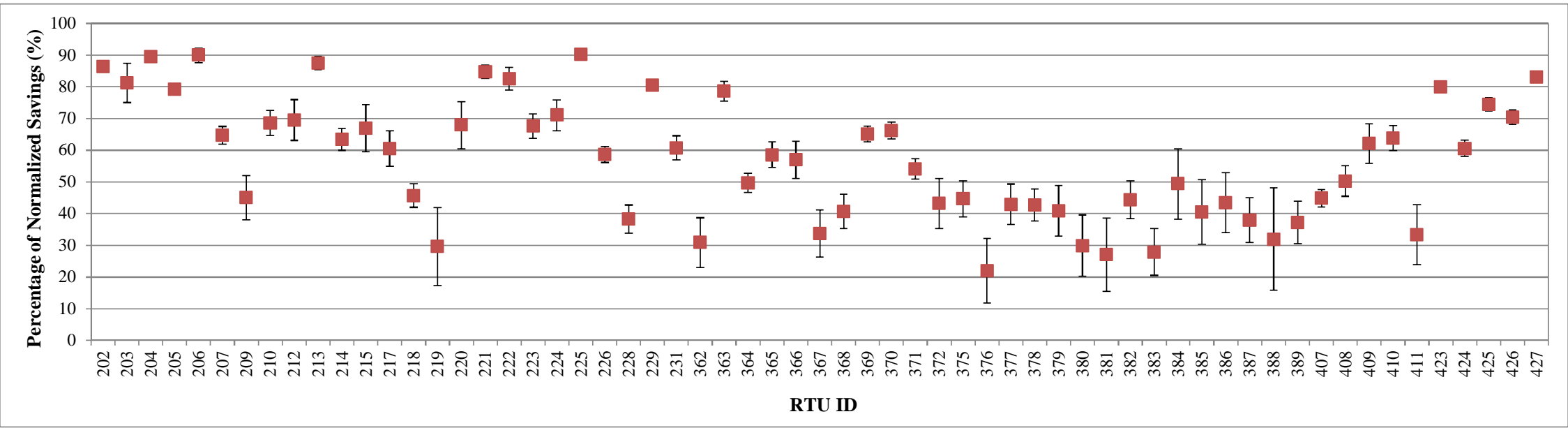

Figure 2: Percent of normalized annual energy savings and uncertainty range at $95 \%$ confidence for each RTU 
Figure 3 shows the frequency distribution of actual and normalized RTU electricity savings. The majority were in the range between $25 \%$ and $90 \%$. The quartiles of actual electricity savings were $38 \%, 50 \%$, and $71 \%$, respectively for the 25 th percentile, the median, and the 75 th percentile. The corresponding quartiles for normalized electricity savings were $43 \%, 59 \%$, and $70 \%$.

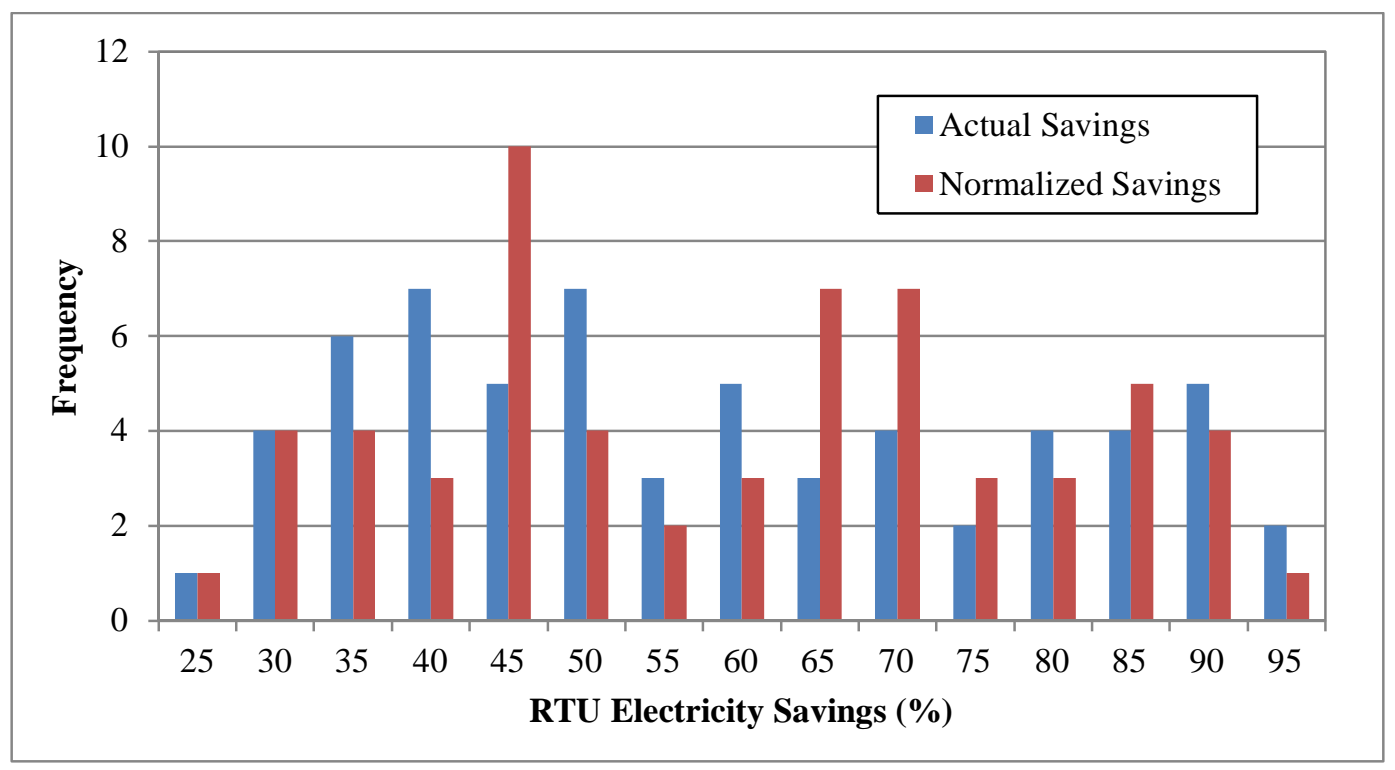

Figure 3: Frequency distribution of actual and normalized RTU electricity savings in percentages

\subsection{Absolute energy savings}

In addition to the percentage of RTU electricity savings, review of the absolute savings is also useful to understand the impact of the advanced controller. The variables that had significant effect on the savings include building type (static pressure and occupancy variations), climate location, unit runtime and the unit size (supply-fan motor). In this paper, the absolute RTU electricity savings are presented as $\mathrm{kWh}$ per RTU run hour ( $\mathrm{kWh} / \mathrm{h})$. The report [10] can be referred to for other normalized results such as $\mathrm{kWh} / \mathrm{h}$ per fan horsepower and kWh per RTU cooling tonnage. The following is a discussion of the absolute energy savings results:

- Actual RTU electricity savings ranged between 0.35 and $7.68 \mathrm{kWh} / \mathrm{h}$, with an average of 2.41 $\mathrm{kWh} / \mathrm{h}$. Most of the RTU electricity savings came from the supply fan, which has electricity savings ranging between $0.32 \mathrm{kWh} / \mathrm{h}$ to $6.64 \mathrm{kWh} / \mathrm{h}$ with an average of $1.95 \mathrm{kWh} / \mathrm{h}$.

- Annual TMY weather normalized savings were in the range between $0.47 \mathrm{kWh} / \mathrm{h}$ and 7.21 $\mathrm{kWh} / \mathrm{h}$, with an average of $2.39 \mathrm{kWh} / \mathrm{h}$. Similar to actual savings, most of the normalized electricity savings also came from the supply fan, which has electricity savings ranging between $0.36 \mathrm{kWh} / \mathrm{h}$ to $7.37 \mathrm{kWh} / \mathrm{h}$ with an average of $2.18 \mathrm{kWh} / \mathrm{h}$.

- For both actual and normalized savings, the electricity savings per hour generally increases with the size of the unit.

Figure 4 compares the frequency distributions of RTU electricity savings per unit run hour for actual and normalized savings. A majority of actual and normalized savings were in the range between 1.0 and 3.5 $\mathrm{kWh} / \mathrm{h}$. The quartiles of absolute actual electricity savings were $1.54,1.98$, and $2.87 \mathrm{kWh} / \mathrm{h}$, respectively for the $25^{\text {th }}$ percentile, the median, and the $75^{\text {th }}$ percentile. The corresponding quartiles for normalized electricity savings were $1.38,1.96$, and $2.84 \mathrm{kWh} / \mathrm{h}$. 


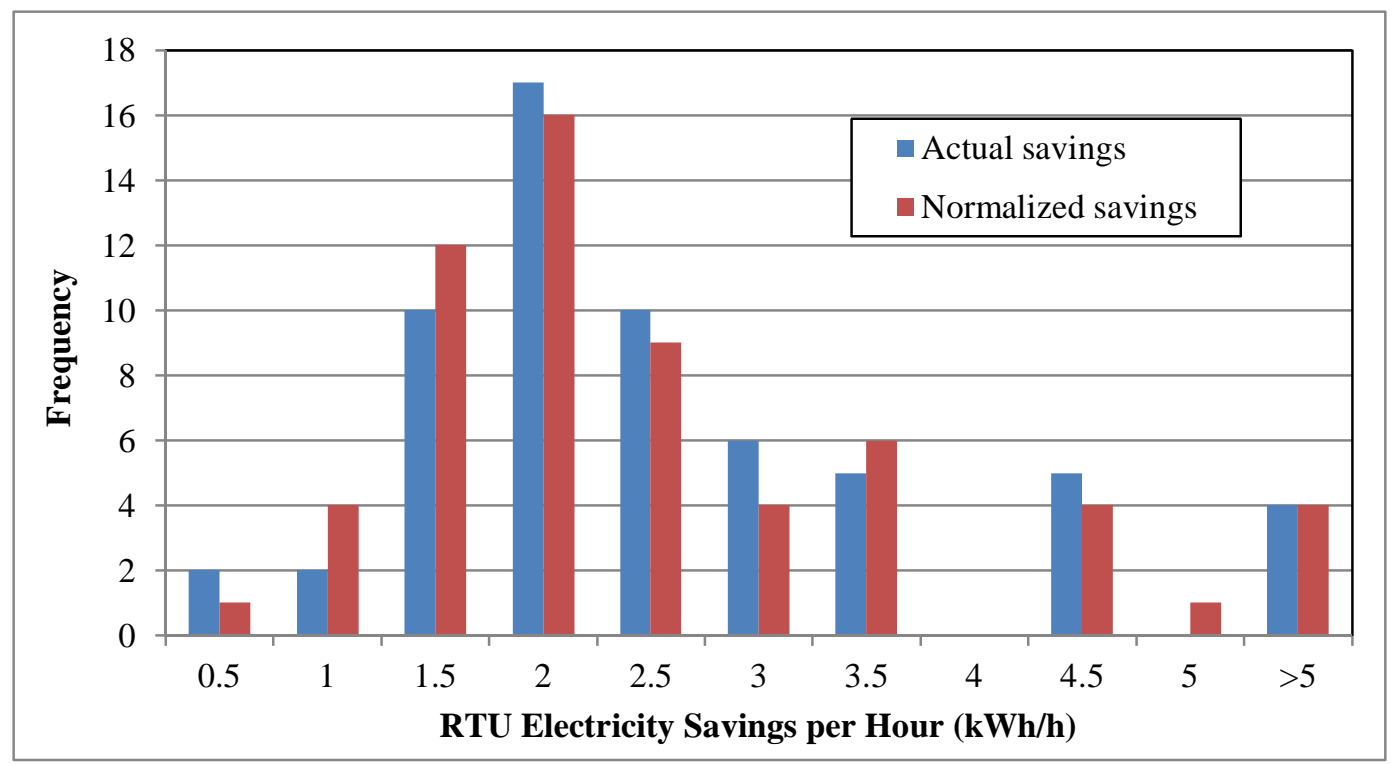

Figure 4: Frequency distribution of RTU electricity savings per unit run hour

When pursuing RTU retrofits with the advanced controller, building owners or utility companies need to estimate the potential electricity savings. Because the RTU size and operational characteristics may differ from those in this field study, it is desirable to have a generic approach to quantify the potential electricity savings. Considering that the fan runtime and the fan motor size were the dominant contributors to the magnitude of the electricity savings from the RTU controller retrofit, a multiple linear regression between these two parameters and the normalized annual electricity savings was conducted, which resulted in the following regression equation:

$R T U E_{\text {annual }}=0.382 *$ RunTime $+4910 *$ FanPower $\quad$,

where $R T U E_{\text {annual }}$ is the annual RTU electricity savings in $\mathrm{kWh}$; RunTime is the annual RTU operation time in hours; FanPower represents the actual (not nameplate) supply fan size in kW.

The regression model had an adjusted coefficient of determination $\left(R^{2}\right)$ of 0.92 , which indicates that RTU runtime and supply-fan size are good predictors of the potential energy savings from the advanced RTU controller retrofit. Figure 5 compares the normalized annual RTU electricity savings calculated from Equation 12 and from the detailed procedure, respectively. This figure visually demonstrates that Equation 12 can be confidently used to predict annual electricity savings. Note that for this analysis, the fan power was physically measured rather than relying on nameplate data. 


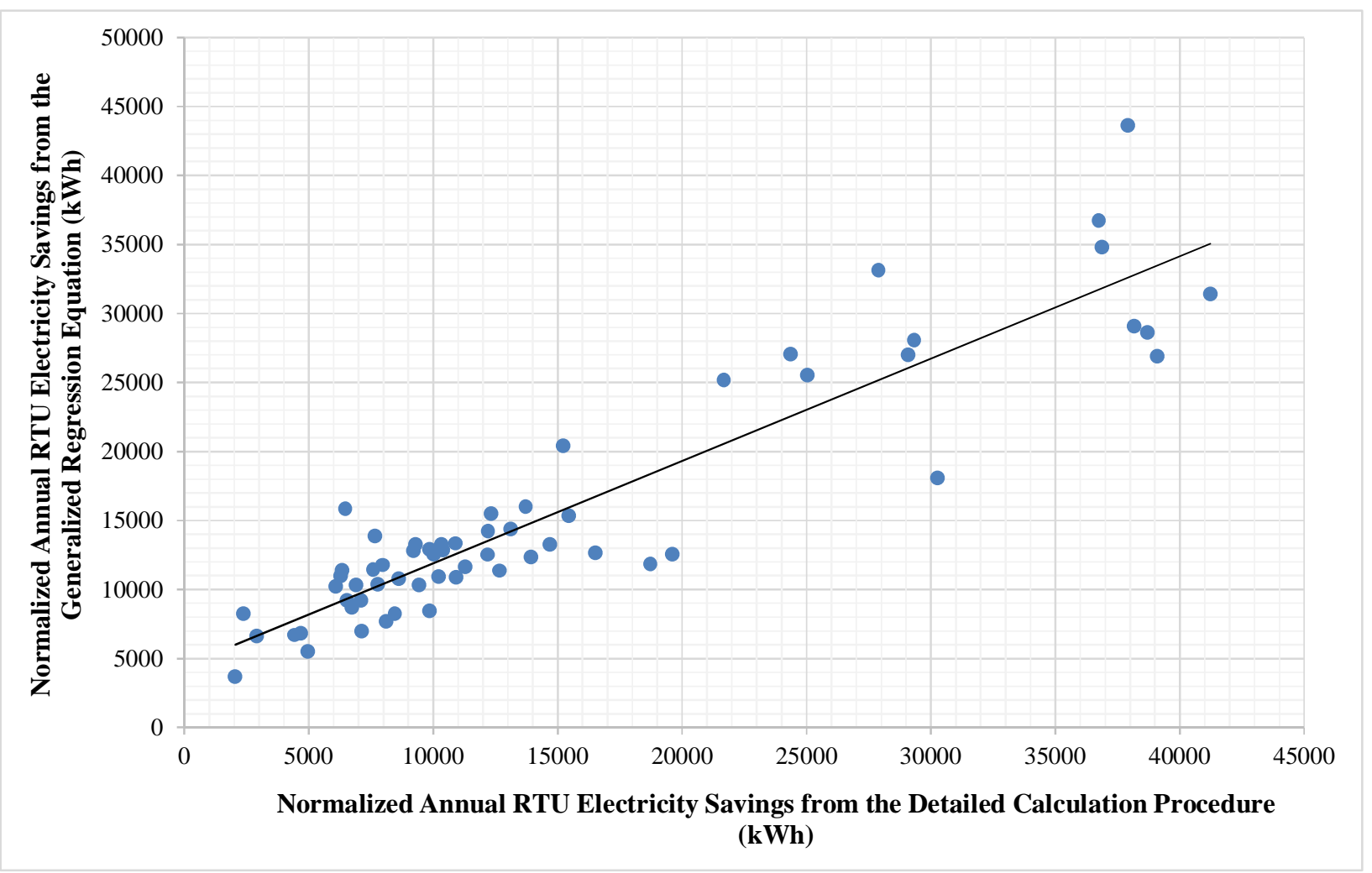

Figure 5: Comparison of predicted normalized annual RTU electricity savings from the simple generalized regression equation vs. the normalized calculated annual savings

\section{Economic analysis}

The major benefit from the advanced RTU controls is electricity savings from fan speed control and the improved economizer control. Although applying demand-controlled ventilation could save gas energy for packaged air conditioners with gas furnace, it was not the focus of this project because gas consumption was not measured to quantify the gas energy savings. Therefore, the economic analysis is based on electricity savings only.

Table 3 provides the capital cost and labor cost associated with the advanced controller retrofit for a single RTU at varying capacities and corresponding supply-fan sizes. The controller cost varied because it includes the VFD cost, and the size of the VFD depends on the size of the supply-fan motor. Labor rate was assumed to be $\$ 125 / \mathrm{h}$, which may vary based on market conditions. The controller costs in Table 3 are from the controller manufacturer's quotes. The labor costs for the controller installation are the quotes from the contractor who installed the controllers for this project.

Table 3: RTU advanced controller installed costs broken down

\begin{tabular}{|c|c|c|c|}
\hline $\begin{array}{c}\text { RTU Cooling } \\
\text { Capacity (kW) }\end{array}$ & $\begin{array}{c}\text { Supply } \\
\text { Fan Size } \\
(\mathbf{k W})\end{array}$ & $\begin{array}{c}\text { Controller } \\
\mathbf{( \$ )}\end{array}$ & $\begin{array}{c}\text { Controller } \\
\text { Labor } \mathbf{( \$ )}\end{array}$ \\
\hline$\leq 18$ & 0.75 & 2,200 & 750 \\
\hline$>18$ and $\leq 35$ & 1.50 & 2,600 & 750 \\
\hline$>35$ and $\leq 53$ & 2.25 & 3,500 & 750 \\
\hline$>53$ and $\leq 70$ & 3.75 & 4,000 & 750 \\
\hline
\end{tabular}




\begin{tabular}{|l|l|l|l|}
$>70$ and $\leq 88$ & 5.63 & 4,142 & 750 \\
\hline
\end{tabular}

Based on the costs outlined in Table 3, a simple payback was calculated for the advanced controller, based on the projected normalized annual energy savings. Three utility rates were used: $0.05 \$ / \mathrm{kWh}, 0.10$ $\$ / \mathrm{kWh}$ and $0.15 \$ / \mathrm{kWh}$. Across all units, the annual average cost savings were $\$ 744, \$ 1,489$ and $\$ 2,233$ for the three considered utility rates, with a corresponding average installed cost of $\$ 4,172$, resulting in average payback period of 6,3 , and 2 years, respectively. Wang et al. [10] provides additional details on the payback period calculation accounting for the metering and monitoring packages.

The simple payback period largely depends on RTU size and RTU runtime. The units with the shortest payback period were either large units (e.g., greater than $53 \mathrm{~kW}$ ) or had the longest operating hours per year. To illustrate the impact of RTU size on the simple payback period, three groups were used based on the cooling capacity: less than $35 \mathrm{~kW}$, between 35 and $53 \mathrm{~kW}$, and greater than 53 tons. The change of simple payback period with utility rates and incentive levels is shown in Figures 6-8, respectively for each of the three RTU groups. These figures lead to the following discussion:

- For units smaller than $35 \mathrm{~kW}$, the average payback period was 3 years or less for utility rates above $\$ 0.12 / \mathrm{kWh}$ when incentives were offered ( 3 years at $25 \%$ incentives and 2 years at $50 \%$ incentives, respectively), and $\$ 0.16 / \mathrm{kWh}$ without incentives.

- For units between $35 \mathrm{~kW}$ and $53 \mathrm{~kW}$, the average payback period was 3 years or less for utility rates above $\$ .09 / \mathrm{kWh}$ when incentives were offered (3.1 years at $25 \%$ incentives and 2.1 years at $50 \%$ incentives, respectively), and $\$ 0.12 / \mathrm{kWh}$ without incentives.

- For units larger than $53 \mathrm{~kW}$, the average payback period was always less than 3 years, with or without incentives.

It is worth noting that although Figures 6-8 and the associated findings were based on the RTU size, the impact of RTU runtime was implicitly considered. For each of the three RTU size groups, the average annual RTU runtime was 5130, 5900 and 7290 hours. The simple payback period needs to be adjusted for RTUs with significantly different runtime than those presented in this work.

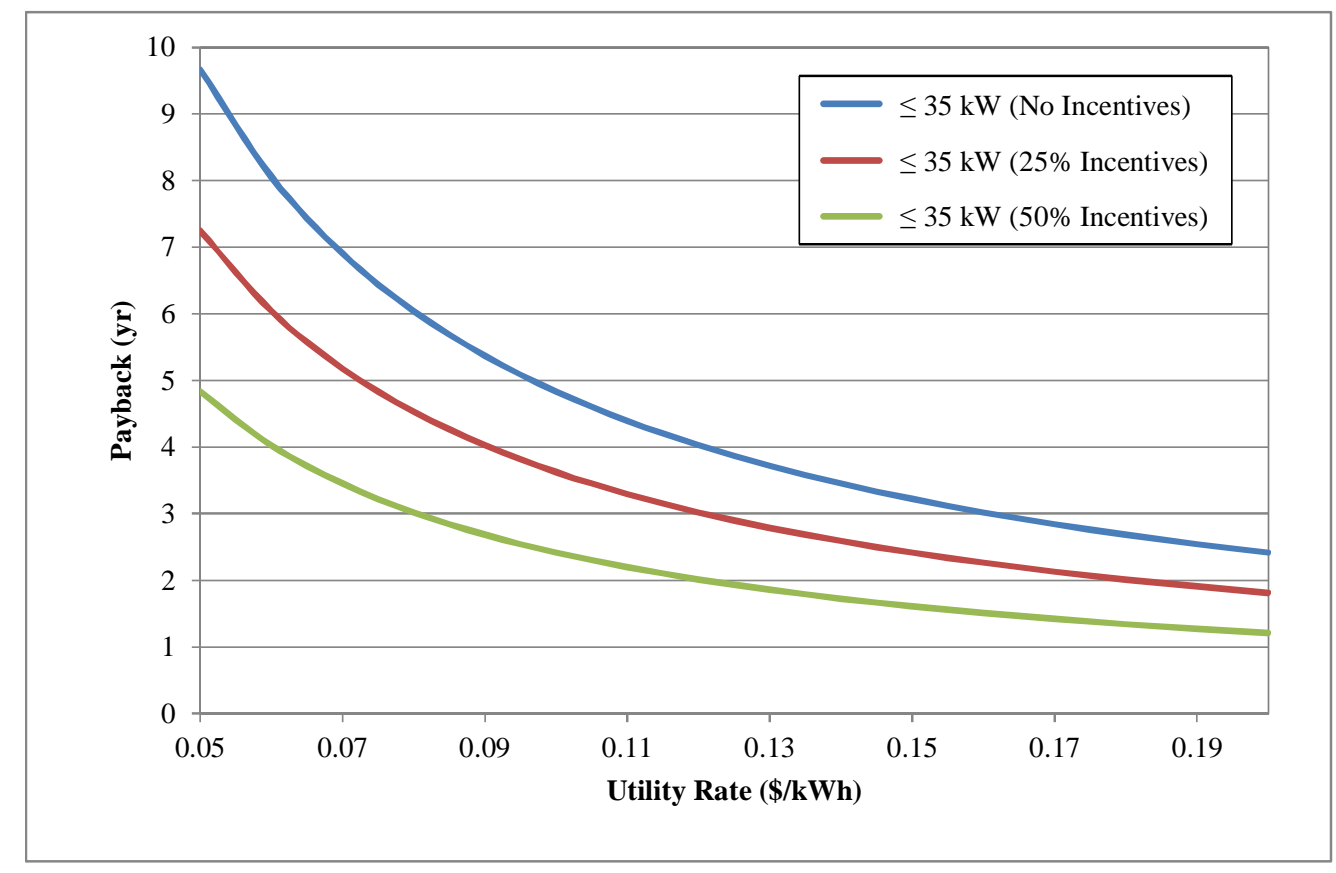


Figure 6: Average payback period for units with cooling capacities less than $35 \mathrm{~kW}$, for varying utility rates

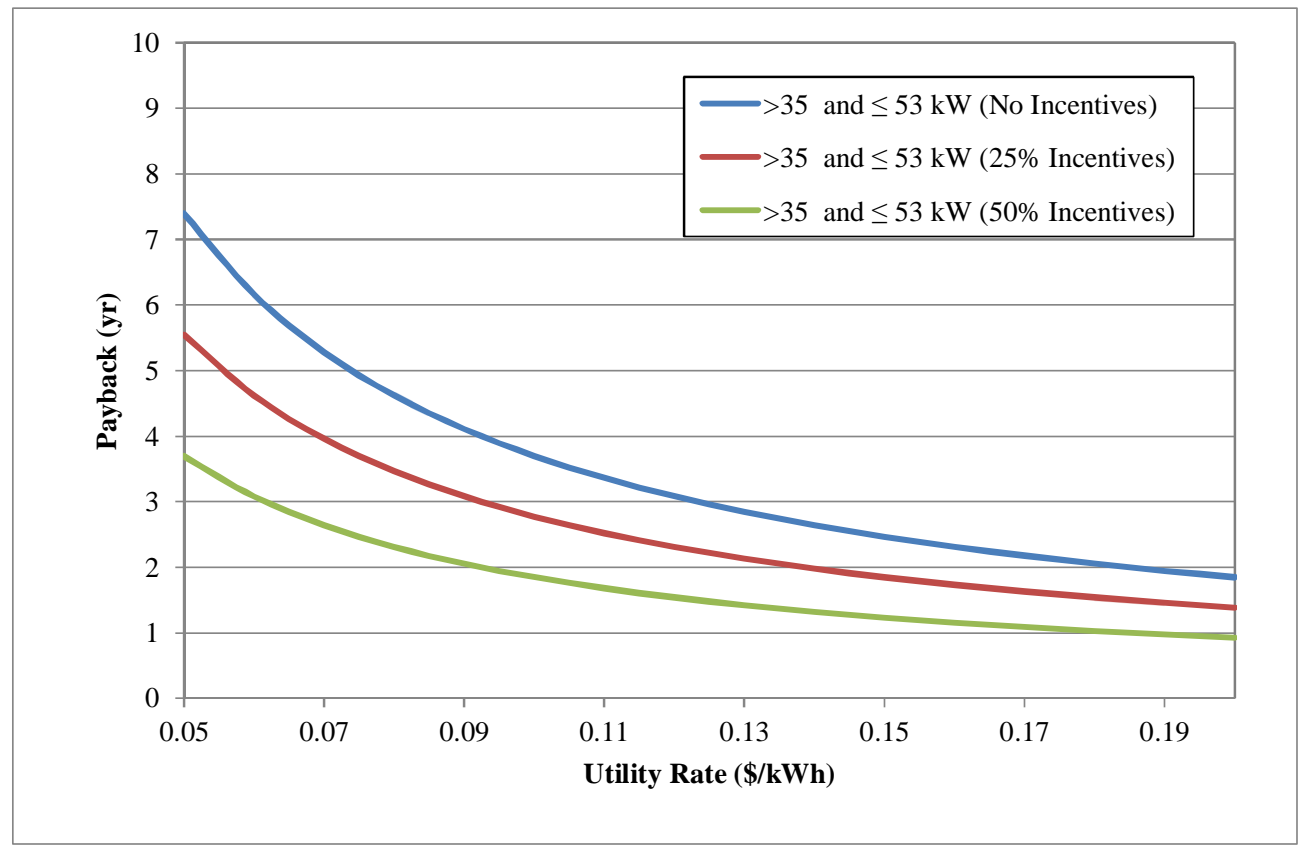

Figure 7: Average payback period for units with cooling capacities between $35 \mathrm{~kW}$ and $53 \mathrm{~kW}$, for varying utility rates

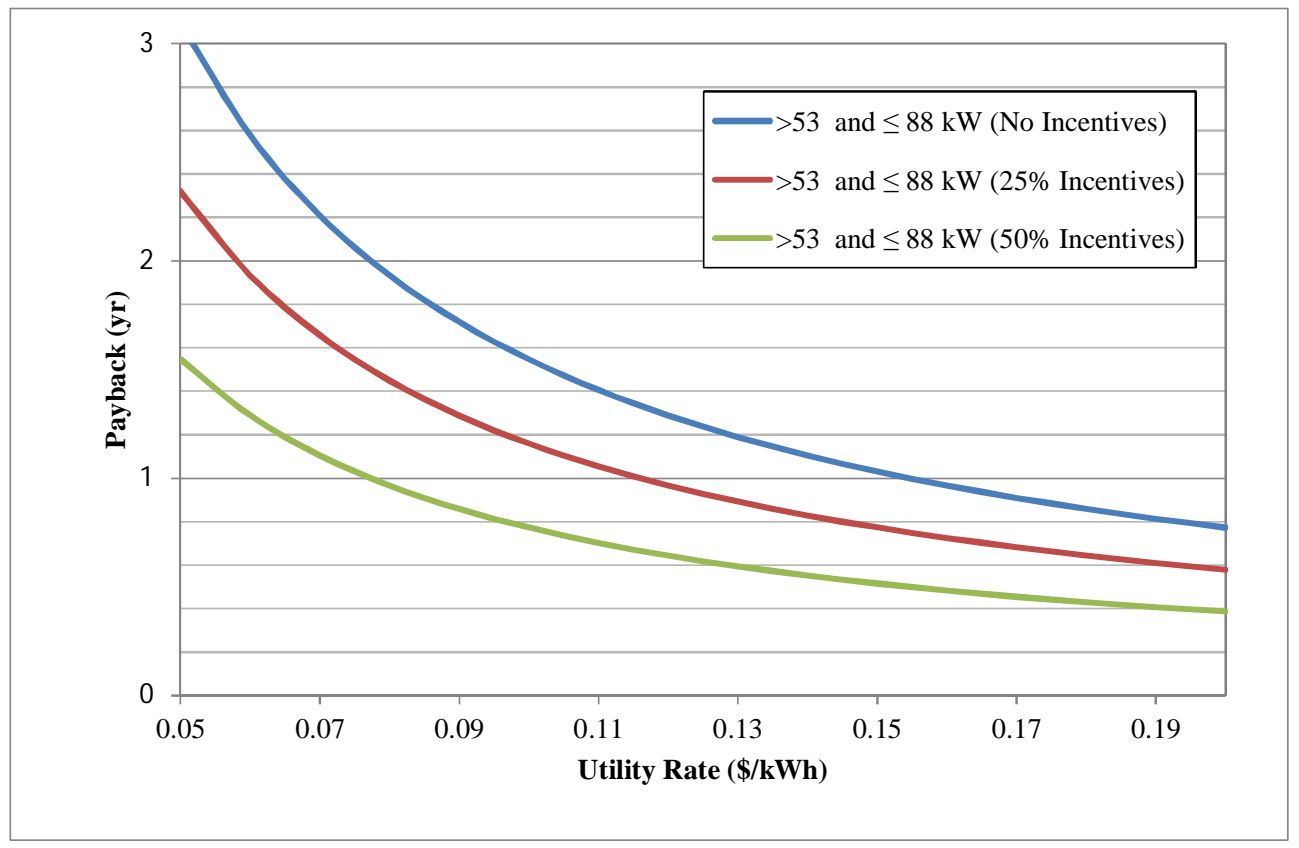

Figure 8: Average payback period for units with cooling capacities between $53 \mathrm{~kW}$ and $88 \mathrm{~kW}$, for varying utility rates

\section{Conclusions}


A total of 66 RTUs on 8 different buildings were retrofitted with a commercially available advanced controller for improving RTU operational efficiency. Of the 66 tested RTUs, 18 were packaged heat pumps and the rest were packaged air conditioners with gas heat. The 8 buildings covered four building types, including mercantile (both retail and shopping malls), office, food sales, and healthcare. These buildings were located in four different climate zones including the warm and coastal climate, the mixed and humid climate, the mixed and marine climate, and the cool and humid climate. All RTUs were monitored for about 1 year with alternating operations (standard vs. advanced controls). The measured actual energy savings, the normalized energy savings, and the savings uncertainties were calculated using the methods described in the ASHRAE Guideline 14. Major findings from this work are highlighted below. These findings apply to all advanced RTU controllers with strategies such as fan speed control, $\mathrm{DCV}$, and enhanced economizer control.

- The advanced controller reduced both actual consumption and normalized consumption by between $22 \%$ and $90 \%$, with an average of $55 \%$ for all RTUs. The majority of RTUs had their electricity savings in the range between $40 \%$ and $90 \%$.

- On average, the fractional savings uncertainty was $25 \%$ for actual savings and $12 \%$ for normalized savings.

- For absolute savings, actual RTU electricity savings was in the range between 0.35 and 7.68 $\mathrm{kWh} / \mathrm{h}$ of unit operation, with an average of $2.41 \mathrm{kWh} / \mathrm{h}$. Normalized annual electricity savings ranged between 0.47 and $7.21 \mathrm{kWh} / \mathrm{h}$ of unit operation, with an average of $2.39 \mathrm{kWh} / \mathrm{h}$.

- RTU runtime and supply-fan motor size are major factors that affect the magnitude of RTU electricity savings from the advanced controller. The generalized regression equation (Eq. 12) presented in this paper can be used to quantify the potential savings.

- For all RTUs, the average payback period was 6, 3, and 2 years, respectively for the three utility rates of $0.05 \$ / \mathrm{kWh}, 0.10 \$ / \mathrm{kWh}$, and $0.15 \$ / \mathrm{kWh}$. These payback periods account for the controller cost and labor to install the controller. Incentives are usually needed to achieve a 3-year simple payback for RTUs with cooling capacities less than $35 \mathrm{~kW}$.

\section{Acknowledgments}

The authors would like to acknowledge the Building Technologies Office of the U.S. Department of Energy and Bonneville Power Administration for funding the study. Transformative Wave Inc. provided significant cost share and helped recruit organizations to participate in the demonstration.

\section{References}

[1] EIA (Energy Information Administration). 2003. Commercial Buildings Energy Consumption Survey 2003. U.S. Department of Energy, Washington, D.C. Last accessed in July 2013 at http://www.eia.doe.gov/emeu/cbecs/contents.html.

[2] Jacobs P., V. Smith, C. Higgins, M. Brost. 2003. "Small commercial rooftops: field problems, solutions and the role of manufacturers." In Proceedings of the 11th National Conference on Building Commissioning, Palm Springs, CA, 2003. National Institute of Building Sciences, Washington, D.C.

[3] Criscione P. 2011. "A dramatic boost for existing RTUs.” E Source Research Brief, TAS-RB-47.

[4] Hart R., J. Callahan, K. Anderson, P. Johanning. "Unitary HVAC premium ventilation upgrade." ASHRAE Transactions, 117 (2011), pp. 517-524 (part 1)

[5] Brandemuel M.J. and J.E. Braun. 1999. "The impact of demand-controlled and economizer ventilation strategies on energy use in buildings." ASHRAE Transactions 105(2): 39-50. 
[6] Wang W., S. Katipamula, Y. Huang, and M.R. Brambley. 2013. "Energy savings and economics of advanced control strategies for packaged air conditioners with gas heat." Energy and Buildings 65:497-507. DOI: 10.1016/j.enbuild.2013.06.033

[7] Wang W., Y. Huang, and S. Katipamula. 2012. Energy Savings and Economics of Advanced Control Strategies for Packaged Heat Pumps. PNNL-21944, Pacific Northwest National Laboratory, Richland, WA.

[8] ASHRAE. 2010. ASHRAE Standard 62.1-2010: Ventilation for Acceptable Indoor Air Quality. American Society of Heating, Refrigerating and Air-Conditioning Engineers Inc., Atlanta, GA.

[9] ASHRAE. 2010. ASHRAE Standard 90.1-2010: Energy Standard for Buildings Except Low-Rise Residential Buildings. American Society of Heating, Refrigerating and Air-Conditioning Engineers Inc. Atlanta, GA.

[10] Wang, W, S. Katipamula, H. Ngo, R.M. Underhill, D.J. Taasevigen, and R.G. Lutes. 2013. Advanced Rooftop Control (ARC) Retrofit: Field-Test Results. PNNL-22656, Pacific Northwest National Laboratory, Richland, WA.

[11] ASHRAE 2002. ASHRAE Guideline 14-2002. Measurement of Energy and Demand Savings. American Society of Heating, Refrigerating and Air-Conditioning Engineers, Atlanta, GA.

[12] Katipamula S., T.A. Reddy, and D.E. Claridge. 1995. "Effect of time resolution on statistical modeling of cooling energy use in large commercial buildings.” ASHRAE Transactions, Vol. 101, Pt 2, pp. 172 - 185.

[13] Taasevigen D.J., S. Katipamula, and W. Koran. 2011. Interval Data Analysis with the Energy Charting and Metrics Tool (ECAM). PNNL-20495, Pacific Northwest National Laboratory, Richland, WA.

[14]Effinger M., J. Anthony, and L. Webster. 2009. "Case Studies in Using Whole Building Interval Data to Determine Annualized Electrical Savings." In Proceedings of the Ninth International Conference for Enhanced Building Operations, Austin, Texas, November, 2009, 13 pages, Texas A\&M University, College Station, TX.

[15] Sunde J., J. Wang, and K. Vlasek. 2011. "Digi RTU Optimizer Case Study: New Technology to Maximum Energy Efficiency." In Proceedings of the ACEEE Summer Study on Energy Efficiency in Industry, 2011, 11 pages, Niagara Falls, NY.

[16] Doebber I., D.J. Dominick, and G. Holland. 2014. RM12-2703 Advanced Rooftop Unit Control Retrofit Kit Field Demonstration. NREL/TP-5500-61072, National Renewable Energy Laboratory, Golden, CO. 